\title{
Multidisciplinary approach in the treatment of osteoid osteoma with radiofrequency ablation
}

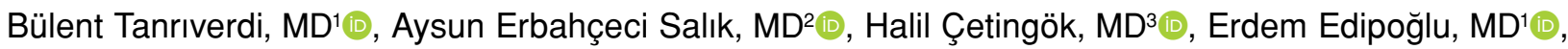

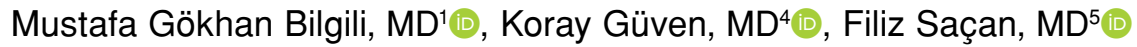 \\ 'Department of Orthopedics and Traumatology, Bakırköy Dr. Sadi Konuk Training and Research Hospital, Istanbul, Turkey \\ ${ }^{2}$ Department of Interventional Radiology, Bakırköy Dr. Sadi Konuk Training and Research Hospital, Istanbul, Turkey \\ ${ }^{3}$ Department of Anesthesiology and Reanimation, Division of Pain Medicine, Istanbul University, Istanbul Faculty of Medicine, Istanbul, Turkey \\ ${ }^{4}$ Department of Radiology, Acıbadem Mehmet Ali Aydınlar University, Medical Faculty, Istanbul, Turkey \\ ${ }^{5}$ Acıbadem Mehmet Ali Aydınlar University, Health Vocational School, Istanbul, Turkey
}

Osteoid osteoma (OO) is a benign tumor that is frequently seen in young people usually in the second and third decade. Tumor localization may be in cortical or cancellous bone. ${ }^{[1]}$ Radiologically, a surrounding sclerotic lesion and a structure called "nidus" are present. Clinically, night pain is typical and frequently responds well to nonsteroidal drugs.

There are many treatment modalities for $\mathrm{OO}$ including medical treatment, percutaneous radiofrequency ablation (RFA) treatment, and open surgical procedures. ${ }^{[1]}$ However, despite all these different treatment methods, recurrence of $\mathrm{OO}$ is a significant problem. The protocol for a successful treatment should be planned in a different way for each patient.

The multidisciplinary approach is an appropriate method for the treatment of various diseases that decreases the rate of morbidity in radiologic interventions as well as in many other fields of medicine. The synergy created by multiple disciplines

Received: October 01, 2019

Accepted: December 18, 2019

Published online: June 18, 2020

Correspondence: Bülent Tanrıverdi, MD. Bakırköy Dr. Sadi Konuk Eğitim ve Araştırma Hastanesi Ortopedi ve Travmatoloji Kliniği, 34147 Bakırköy İstanbul, Türkiye.

E-mail: drbulenttanriverdi@gmail.com

Doi: $10.5606 /$ ehc. 2020.71413

Citation: Tanrıverdi B, Erbahçeci Salık A, Cetingök H, Edipoğlu E, Bilgili MG, Güven K, et al. Multidisciplinary approach in the treatment of osteoid osteoma with radiofrequency ablation. Jt Dis Relat Surg 2020;31(2):255-259.

\section{ABSTRACT}

Objectives: This study aims to present the importance of a multidisciplinary approach to radiofrequency ablation (RFA) treatment in osteoid osteoma $(\mathrm{OO})$ patients by a team of experts in their field in preventing recurrence and complications.

Patients and methods: For this retrospective study, a team of two orthopedists, two interventional radiologists, and one anesthesiologist was established in January 2013 to manage the diagnosis, follow-up, and treatment process of patients with $\mathrm{OO}$ at Bakırköy Dr. Sadi Konuk Training and Research Hospital. A total of 27 patients (15 males, 12 females; mean age 22.9 years; range, 9 to 54 years) were treated by this team between February 2013 and September 2016. The anatomic localization included iliac crest in four patients, the femur in 12 patients, fibula in two patients, humerus in three patients, radius in one patient, tibia in three patients, talus in one patient, and metacarpal in one patient. The procedures were carried out by the same interventional radiologists, same orthopedic surgeons, and same anesthesiologist in the computed tomography (CT) unit under aseptic conditions. After appropriate anesthesia for the localization of OO, the patient was positioned on the CT bed and the localization of the lesion was confirmed with a CT scan mapping. Then, a bone penetration cannula was advanced and bone cortex was penetrated with a charged motor and Kirschner (K)-wire. When the cannula reached the nidus, it was replaced with RFA probe. Ablation of the nidus was performed for five minutes at $90^{\circ} \mathrm{C}$.

Results: The mean follow-up period was 46 months (range, 25 to 66 months). Patients were evaluated with visual analog scale (VAS) scores preoperatively and at postoperative $15^{\text {th }}$ day, sixth month, and first year. In the last evaluation of the study data, the patients were called by telephone and questioned whether there were any changes in their final status. The mean preoperative VAS score was 7.2. The mean postoperative VAS scores of the $15^{\text {th }}$ day, sixth month, and first year were $1.3,0.6$, and 0 , respectively. In the last follow-up, the OO-related pain completely disappeared and none of the patients had any recurrence. There was a significant difference between preoperative and postoperative $15^{\text {th }}$ day and sixth month VAS score measurements.

Conclusion: Radiofrequency ablation treatment of OOs is a minimally invasive, safe, low-cost, and efficient method. We believe that with experienced teams and appropriate planning, RFA will take part in practice as the standard treatment of $\mathrm{OO}$.

Keywords: Ablation, osteoid osteoma, radiofrequency. 
involved can prevent potential complications. In the treatment of OOs with RFA, it is a must to reach inside the nidus in order to burn the lesion entirely. By the help of the devices such as power drills, an experienced orthopedist perforates the bone first, entering into the lesion from the marked point, tactilely sensing the difference in the textures around nidus area and sclerotic area and determining how far inside the RF should go in the nidus. Then, the burning procedure can be performed appropriately after confirming that the probe entered inside the nidus using computed tomography (CT). Additionally, to ensure that this intervention can be performed without any interruptions and maintain the patient's comfort, the patient should receive proper anesthesia. The careful application of all of these steps may help decrease the likelihood of recurrence. In this study, we aimed to present the importance of a multidisciplinary approach to RFA treatment in OO patients by a team of experts in their field in preventing recurrence and complications.

\section{PATIENTS AND METHODS}

For this retrospective study, a team of two orthopedists, two interventional radiologists, and one anesthesiologist was established in January 2013 to manage the diagnosis, follow-up, and treatment process of patients with $\mathrm{OO}$ at Bakırköy Dr. Sadi Konuk Training and Research Hospital. Between February 2013 and September 2016, 27 patients (15 males, 12 females; mean age 22.9 years; range, 9 to 54 years) who were admitted to our orthopedics clinic, diagnosed with OO, and who underwent RFA treatment were treated by this team. A detailed anamnesis was taken from all patients and night pain, pain localization, and nonsteroidal drug response were questioned. Then, all patients underwent direct radiography and CT. The diagnosis of $\mathrm{OO}$ was established by one radiologist and one orthopedic surgeon by evaluating the clinical and radiological findings separately. The mean follow-up period was 46 months (range, 25 to 66 months). The anatomic localization included iliac crest in four patients, femur in 12 patients, fibula in two patients, humerus in three patients, radius in one patient, tibia in three patients, talus in one patient, and metacarpal in one patient (Table I). After the necessary anesthesia preparations and examinations, all patients were informed about the procedure. Later, the whole team was present in the interventional radiology department of our hospital and the operation was performed. The study protocol was approved by the Bakırköy Dr. Sadi Konuk Training and Research
Hospital Ethics Committee (approval number: 2018-13-02, date: 23 July 2018). A written informed consent was obtained from each patient. The study was conducted in accordance with the principles of the Declaration of Helsinki.

The procedures were carried out by the same interventional radiologists, orthopedic surgeons, and anesthesiologist in the CT unit under aseptic conditions. After ultrasound-guided brachial plexus block for upper extremity or spinal anesthesia for lower extremity, the patient was positioned on the CT bed and the localization of the lesion was confirmed with a CT scan mapping. The entry point on the skin was marked after a CT scan with the placement of multiple radiopaque skin marker. After aseptic conditions were provided, a small skin incision was performed. Then, a bone penetration cannula (RITA StarBurst Access System, 11G, AngioDynamics Inc., Marlborough, MA, USA) was advanced and bone cortex was penetrated with a charged motor and Kirschner (K)-wire. When the cannula reached the nidus, it was replaced with RFA probe (UniBlate, AngioDynamics Inc., Marlborough, MA, USA). Ablation of the nidus was performed for 5 minutes at $90^{\circ} \mathrm{C}$. After the procedure, the cannula and probe were removed. All patients were followed up in the orthopedics clinic for one night.

All patients were discharged the next day. Postoperative activity restriction was recommended for patients with OO lesions in the lower extremity long bone. They were allowed to return to their daily lives with partial load. No plaster, splint or crutches were provided.

Patients were evaluated with visual analog scale (VAS) score preoperatively and at postoperative $15^{\text {th }}$ day, sixth month, and first year. In the last evaluation of the study data, the patients were called by telephone and questioned whether there were any changes in their final status. The complaint of pain, which is an important criterion in the clinic and diagnosis of $\mathrm{OO}$, was questioned particularly for the pathology region at the last evaluation.

\section{Statistical analysis}

The statistical analyses were performed with the Number Cruncher Statistical System (NCSS) 11 statistical software (2017, Kaysville, Utah, USA). A $p$ value $<0.05$ was considered statistically significant.

\section{RESULTS}

None of the patients had complications (hematoma in the intervention site, nerve damage, fracture or 


\begin{tabular}{|c|c|c|c|c|c|c|c|}
\hline \multicolumn{8}{|c|}{$\begin{array}{c}\text { TABLE I } \\
\text { Patients' details, anatomic localizations, and visual analog scale scores }\end{array}$} \\
\hline Patient & Age/Gender & Side & Anatomic localization & Preop VAS & $15^{\text {th }}$ day VAS & $6^{\text {th }}$ month VAS & $1^{\text {st }}$ year VAS \\
\hline 1 & $20 / F$ & L & Iliac bone & 8 & 2 & 1 & 0 \\
\hline 2 & $54 / F$ & $\mathrm{R}$ & Distal fibula & 7 & 1 & 0 & 0 \\
\hline 3 & $9 / F$ & L & Proximal femur & 8 & 2 & 0 & 0 \\
\hline 4 & $12 / \mathrm{M}$ & $\mathrm{R}$ & Proximal femur & 7 & 1 & 1 & 0 \\
\hline 5 & $10 / \mathrm{M}$ & L & Distal femur & 8 & 1 & 1 & 0 \\
\hline 6 & $9 / F$ & $\mathrm{R}$ & Fibula & 7 & 2 & 1 & 0 \\
\hline 7 & $12 / \mathrm{M}$ & L & Distal femur & 6 & 1 & 1 & 0 \\
\hline 8 & $17 / M$ & L & Distal humerus & 7 & 1 & 0 & 0 \\
\hline 9 & $16 / F$ & $\mathrm{R}$ & Proximal femur & 8 & 2 & 0 & 0 \\
\hline 10 & $9 / M$ & L & Talus & 7 & 1 & 0 & 0 \\
\hline 11 & $11 / \mathrm{F}$ & $\mathrm{R}$ & Tibia & 8 & 1 & 0 & 0 \\
\hline 12 & $21 / M$ & L & Metacarpal & 6 & 1 & 0 & 0 \\
\hline 13 & $25 / M$ & L & Iliac bone & 7 & 2 & 0 & 0 \\
\hline 14 & $31 / \mathrm{M}$ & L & Femur & 7 & 1 & 1 & 0 \\
\hline 15 & 33/M & $\mathrm{R}$ & Proximal humerus & 7 & 2 & 1 & 0 \\
\hline 16 & $50 / F$ & $\mathrm{R}$ & lliac bone & 7 & 1 & 1 & 0 \\
\hline 17 & $48 / \mathrm{M}$ & $\mathrm{R}$ & Proximal humerus & 8 & 2 & 1 & 0 \\
\hline 18 & $14 / F$ & L & Distal femur & 7 & 1 & 1 & 0 \\
\hline 19 & $19 / M$ & $\mathrm{R}$ & Femur & 6 & 0 & 0 & 0 \\
\hline 20 & $20 / F$ & L & Femur & 8 & 1 & 1 & 0 \\
\hline 21 & $17 / M$ & $\mathrm{R}$ & Radius & 7 & 2 & 1 & 0 \\
\hline 22 & $17 / F$ & L & Tibia & 7 & 2 & 1 & 0 \\
\hline 23 & $25 / M$ & $\mathrm{R}$ & Tibia & 7 & 2 & 1 & 0 \\
\hline 24 & $22 / M$ & L & Proximal femur & 8 & 2 & 1 & 0 \\
\hline 25 & $24 / M$ & L & Proximal femur & 8 & 1 & 1 & 0 \\
\hline 26 & $20 / F$ & $\mathrm{R}$ & Distal femur & 7 & 0 & 0 & 0 \\
\hline 27 & $42 / F$ & $\mathrm{R}$ & Iliac bone & 7 & 1 & 1 & 0 \\
\hline
\end{tabular}

fissure in the bone, etc.) related to anesthesia or intervention. Nonsteroidal anti-inflammatory drugs were used only in patients who had local pain in the K-wire and probe entrance area after the effect of anesthesia disappeared.

The mean preoperative VAS score of the patients was 7.2. The mean postoperative VAS scores of the $15^{\text {th }}$ day, sixth month, and first year were 1.3, 0.6 , and 0 , respectively. In the last follow-up, the OO-related pain completely disappeared and none of our patients had any recurrence. No further imaging was required.

There was a significant difference between preand postoperative $15^{\text {th }}$ day and sixth month VAS score measurements. Wilcoxon signed-rank test was used to determine which two measurements caused significant difference. There was a significant difference between all measurement times. When the median values were examined, it was found that the preoperative evaluation had the highest value while the postoperative sixth month had the lowest value. Pain level was found to decrease with time. At the end of the $12^{\text {th }}$ month measurements, all patients stated pain severity as zero.

\section{DISCUSSION}

The key to success in the treatment of OO with RFA is to reach the nidus fully and perform ablation in the right place. We believe that the application of this procedure by experienced persons increases 
our success, thus is the most important factor in preventing recurrence and complications.

It has been reported that the success rate of surgical interventions on OOs is approximately $88-100 \%$ while the rate of recurrence is $4.5-25 \% .{ }^{[2,3]}$ The recurrence rate of post-RFA treatment has been reported to be approximately $5-12 \%{ }^{[4,5]}$ Rimondi et al. ${ }^{[6]}$ have reported recurrence rates as $4 \%$ in their publications. The recurrence rate significantly decreases after six months and reaches very low rates after two years. ${ }^{[4]}$ We did not observe any recurrence in our patients during the follow-up period of 46 months. ${ }^{[7]}$

The RFA treatment should be carefully applied on surface lesions and lesions on small bones such as hand and foot because of the risk of damaging the skin, and on vertebral lesions because of the risk of thermal radiation harm on the spinal cord or nerve roots. Vanderschueren et al. ${ }^{[8]}$ concluded that even though there is the possibility of thermal risk, OOs can be safely treated with RF method. They reported that out of 97 patients involved in their study, the only complication observed was skin necrosis resulting in fistula in one patient. Lanza et al. ${ }^{[9]}$ have evaluated 27 articles including a total of 1,772 patients and reported that 12 of 44 patients with complications had skin burns. In our cases, RFA was carefully applied on surface lesions such as radius, fibula and metacarpus lesions, and no procedurerelated complications were observed.

There are many articles in the literature indicating that CT-guided RFA can be performed under general and local anesthesia. Complications related to anesthesia are also mentioned in these publications. ${ }^{[10-14]}$ Rosenthal et al., ${ }^{[11]}$ in their series of interventions in 263 patients under general anesthesia, have observed asymptomatic pulmonary aspiration in one patient and cardiac arrest in another patient. Torriani and Rosenthal ${ }^{[13]}$ have performed interventions under general anesthesia and noted an unexpected significant tachycardia and tachypnea while entering the biopsy cannula into the tumor. Pinto et al. ${ }^{[14]}$ have stated that $50 \%$ of their patients in their studies of interventions under general anesthesia had experienced increased heart rate, blood pressure, and respiratory rate and that these symptoms confirmed that they entered into the nidus. In our studies, we used either the ultrasound-guided brachial plexus block or spinal anesthesia to avoid the potential risks related to general anesthesia and also the risk of insufficiency of local anesthesia. We did not observe any such symptoms or any anesthesiarelated complications in our patients who received regional anesthesia and were monitored throughout the intervention.

There are various publications in the literature stating that the period for pain relief ranges between one to 15 days. ${ }^{[15-17]}$ During the first evaluation on the $15^{\text {th }}$ postoperative day, we examined the pain relief period in our patients and determined that it varies between two to eight days (average, 4.4 days). These findings are similar to the literature. ${ }^{[15,17]}$

Compared with the available literature, the low number of cases, the absence of a control group, and the absence of histopathologic verifications may be considered as the weaknesses of our study. Although having no histopathologic verification in RFA treatment of OOs is seen as a disadvantage, Vanderschueren et al. ${ }^{[8]}$ have stated that they took samples for histopathologic examination before applying RF; however, such examination did not provide any histopathologic diagnosis in $62-64 \%$ of their patients. ${ }^{[1,18]}$ In their article, Rimondi et al. ${ }^{[6]}$ have reported that only $17 \%$ of the biopsy was diagnostic and histological confirmation may not be necessary in typical cases. This suggests that the absence of histopathologic verification for the OO patients may not be considered a significant disadvantage. The diagnosis of OOs based on clinical and radiologic symptoms should be considered sufficient. Many authors acknowledge that clinical and radiological findings are sufficient and biopsy is not needed. ${ }^{[19]}$

The facts that the diagnosis, treatment, and follow-up of all patients in our study were performed by the same team and that no recurrence or complications were observed are the strengths of our study. Given that the success of this treatment depends on applying the RF correctly in the appropriate place, the importance and necessity of a multidisciplinary approach that includes the maintenance of patient comfort by appropriate anesthesia, assessment by an experienced radiologist whether the lesion and probe are correctly located, and the use of K-wire by a senior orthopedist to pass through the cortex around the lesion before penetrating the probe can be better understood. Huang, in his publication presenting RFA treatment in OOs in difficult-to-reach areas, has mentioned the importance of perforation of the cortex. ${ }^{[20]}$

In conclusion, in current oncologic orthopedics, RFA treatment of $\mathrm{OO}$ is a minimally invasive, safe, lower-cost, and efficient method. The most important stage is to reach the lesion without causing any harm to the surrounding tissues and any complications. Planning and experience come to the fore at this point. We believe that with 
experienced teams and appropriate planning, RFA will take part in practice as the standard treatment of OO.

\section{Declaration of conflicting interests}

The authors declared no conflicts of interest with respect to the authorship and/or publication of this article.

\section{Funding}

The authors received no financial support for the research and/or authorship of this article.

\section{REFERENCES}

1. Heck RK Jr, Toy PC. Benign Bone Tumors and Nonneoplastic Conditions Simulating Bone Tumors. In: Canale ST, Beaty JH, editors. Campbell's Operative Orthopaedics. Philadelphia: CV Mosby; 2013. p. 859-86.

2. Cantwell CP, Obyrne J, Eustace S. Current trends in treatment of osteoid osteoma with an emphasis on radiofrequency ablation. Eur Radiol 2004;14:607-17.

3. Lee EH, Shafi M, Hui JH. Osteoid osteoma: a current review. J Pediatr Orthop 2006;26:695-700.

4. Rosenthal DI, Alexander A, Rosenberg AE, Springfield D. Ablation of osteoid osteomas with a percutaneously placed electrode: a new procedure. Radiology 1992;183:29-33.

5. Sim FH, Dahlin CD, Beabout JW. Osteoid-osteoma: diagnostic problems. J Bone Joint Surg [Am] 1975;57:154-9.

6. Rimondi E, Mavrogenis AF, Rossi G, Ciminari R, Malaguti C, Tranfaglia $\mathrm{C}$, et al. Radiofrequency ablation for nonspinal osteoid osteomas in 557 patients. Eur Radiol 2012;22:181-8.

7. Atik OŞ. Is there something new and interesting in my article? Eklem Hastalik Cerrahisi 2019;30:69.

8. Vanderschueren GM, Taminiau AH, Obermann WR, Bloem JL. Osteoid osteoma: clinical results with thermocoagulation. Radiology 2002;224:82-6.

9. Lanza E, Thouvenin Y, Viala P, Sconfienza LM, Poretti D, Cornalba $\mathrm{G}$, et al. Osteoid osteoma treated by percutaneous thermal ablation: when do we fail? A systematic review and guidelines for future reporting. Cardiovasc Intervent Radiol 2014;37:1530-9.
10. Yip PS, Lam YL, Chan MK, Shu JS, Lai KC, So YC. Computed tomography-guided percutaneous radiofrequency ablation of osteoid osteoma: local experience. Hong Kong Med J 2006;12:305-9.

11. Rosenthal DI, Hornicek FJ, Torriani M, Gebhardt MC, Mankin HJ. Osteoid osteoma: percutaneous treatment with radiofrequency energy. Radiology 2003;229:171-5.

12. Çakar M, Esenyel CZ, Seyran M, Tekin AÇ, Adaş M, Bayraktar $\mathrm{MK}$, et al. Osteoid osteoma treated with radiofrequency ablation. Adv Orthop 2015;2015:807274.

13. Torriani M, Rosenthal DI. Percutaneous radiofrequency treatment of osteoid osteoma. Pediatr Radiol 2002;32:615-8.

14. Pinto $\mathrm{CH}$, Taminiau AH, Vanderschueren GM, Hogendoorn PC, Bloem JL, Obermann WR. Technical considerations in CT-guided radiofrequency thermal ablation of osteoid osteoma: tricks of the trade. AJR Am J Roentgenol 2002;179:1633-42.

15. Karagöz E, Özel D, Özkan F, Özel BD, Özer Ö, Coşkun ZÜ. Effectiveness of Computed Tomography Guided Percutaneous Radiofrequency Ablation Therapy for Osteoid Osteoma: Initial Results and Review of the Literature. Pol J Radiol 2016;81:295-300.

16. Woertler K, Vestring T, Boettner F, Winkelmann W, Heindel W, Lindner N. Osteoid osteoma: CT-guided percutaneous radiofrequency ablation and follow-up in 47 patients. J Vasc Interv Radiol 2001;12:717-22.

17. Lindner NJ, Ozaki T, Roedl R, Gosheger G, Winkelmann W, Wörtler K. Percutaneous radiofrequency ablation in osteoid osteoma. J Bone Joint Surg [Br] 2001;83:391-6.

18. Vanderschueren GM, Taminiau AH, Obermann WR, van den Berg-Huysmans AA, Bloem JL. Osteoid osteoma: factors for increased risk of unsuccessful thermal coagulation. Radiology 2004;233:757-62.

19. Campanacci M, Ruggieri P, Gasbarrini A, Ferraro A, Campanacci L. Osteoid osteoma. Direct visual identification and intralesional excision of the nidus with minimal removal of bone. J Bone Joint Surg [Br] 1999;81:814-20.

20. Huang AJ. Radiofrequency Ablation of Osteoid Osteoma: Difficult-to-Reach Places. Semin Musculoskelet Radiol 2016;20:486-95. 